\title{
Reflexiones sobre la fillosofía y el Derecho
}

Luisa Escobar Delgado*

http://dx.doi.org/10.21503/lex.v10i9.382

Abogada por la Universidad de San Martín de Porres. Con maestría en Derecho Civil doctorado por la Universidad Alas Peruanas. Profesora de los cursos de Derecho Civil y Derecho Procesal Civil en la UAP.

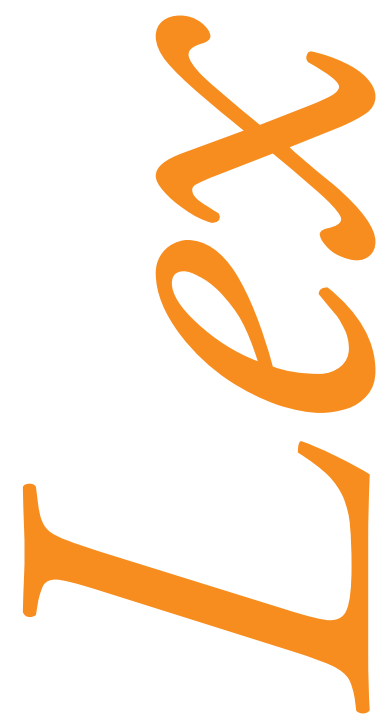



El ignorante afirma, el sabio duda y reflexiona. ARistóteles (384 AC - 322 AC), filósofo griego.

\section{Introducción}

La filosofía es la actividad en la que nos embarcamos (a veces sin quererlo) cuando nos ponemos a pensar críticamente sobre los conceptos, creencias y procedimientos que utilizamos habitualmente.

La filosofía es una actividad que consiste en tratar de pensar correctamente, evitando confusiones, detectando ambigüedades, diferenciando las distintas cuestiones relacionadas con un problema para tratarlas por separado, explicitando las distintas alternativas y construyendo argumentos sólidos para defender las opciones que finalmente se elijan. En consecuencia, no es posible aprender filosofía solo leyendo libros o escuchando conferencias; debemos necesariamente lanzarnos a la acción.

Es una realidad que el Derecho es un fenómeno complejo, que lo jurídico no se agota en una realidad simple e individual. La filosofía del Derecho es aquella rama de la filosofía que concierne al Derecho; por lo tanto, la filosofía del Derecho es una disciplina cuyo objeto de conocimiento fundamental es el conocimiento de lo jurídico. El conocimiento que se adquiere con base en la filosofía del Derecho es, en sí mismo, conocimiento jurídico, pero no como representación de las instituciones jurídicas, sino como plano problemático sobre cómo el Derecho puede ser entendido. La filosofía del Derecho no tanto ordena el Derecho vigente sino que mira los asuntos reflexionando sobre esto; no crea los documentos sino deslinda lo que es Derecho de lo que no es Derecho.

La filosofía es importante porque lo que pensamos sobre aquello que hacemos habitualmente resulta crucial para entender por qué lo hacemos de esa manera, o incluso puede resultar determinante a la hora de tomar la decisión de continuar haciéndolo; por lo tanto, reflexionaremos con el desarrollo de los siguientes concepciones filosóficas sobre la filosofía y el Derecho. 


\section{Filosofía del Derecho a partir de la razón}

"Nosotros queremos proteger y defender los logros de la modernidad, en especial el racionalismo" (5), por lo que es más que pertinente reivindicar a la razón como el uso adecuado del entendimiento, concibiendo a este último como el conjunto de facultades intelectivas y sensibles propias de la humanidad, en procura de una mejor comprensión de la existencia. Nótese que le ha sido atribuida a la razón una función develadora de sentidos y perspectivas que, aunada a un carácter de intersubjetividad y discutibilidad, permitirá dirigir el accionar del hombre a un mejor estadio; en cambio, si el vocablo empleado hubiese sido explicación, se estaría ante una definición realmente plana y equívoca de la razón, para la cual son válidas todas las críticas y cuestionamientos que han posibilitado el tránsito de la modernidad hacia la posmodernidad que acusan ciertos pensadores.

Esta equivocada interpretación de los ideales propugnados en el Siglo de las Luces ha llevado a que, por ejemplo, William Ospina presente un pesimista y decepcionante diagnóstico: "Un mundo así reducido a sus manifestaciones más evidentes y a sus mecanismos más útiles, solo promete la muerte del espíritu humano" (6). Pero hay que recalcar que el uso de la razón como medio comprensivo o interpretativo tiene entre uno de sus grandes logros la caracterización de los derechos naturales: absolutos, universales y suprahistóricos (7), los cuales una vez refinados desembocaron en el discurso de los derechos humanos.

\section{Filosofía del Derecho: racionalidad formal y racionalidad material}

Ahora bien, concretamente en la filosofía del Derecho, esta malinterpretación de la racionalidad trajo consigo un exclusivo enfoque lógico-formal, paradigma bajo el cual se desarrollaría gran parte del trabajo filosófico-jurídico. En este orden de ideas, el estudio y la discusión se centraron únicamente en estructuras lógicas y conceptuales, reduciéndose así la filosofía del Derecho a un mero análisis formal, con lo que cayó en un cientificismo que legitimaría al pernicioso formalismo que aún se encuentra presente en algunos estrados judiciales y que es menester moderar.

Bajo estos supuestos, la filosofía jurídica devino en una teoría general del Derecho, desdibujando así su propósito de hallar el Derecho justo o correcto. Como bien lo indica el profesor alemán Arthur Kaufmann, cualquier intento de tratar asuntos relativos al contenido del Derecho era condenado sin vacilación como anticientífico y antikantiano (5), merced al tenor político que dichos temas revisten, e igualmente se agregaba que la aplicación del Derecho encaja necesariamente en un proceso lógico, una subsunción, por lo que no era necesario acudir a mecanismos extralegales para su formación y ejecución: “(...) el proceso de creación jurídica muestra una estructura esencial más complicada, que contiene también momentos productivos, dialécticos, posiblemente intuitivos, en todo caso no exclusivamente 
lógico-formales, y que [el juez nunca infiere la decisión solo de la ley], sino que llega al caso siempre con un determinado preconcepto, establecido principalmente por la tradición y la situación [se ignoró completamente]". (5)

Resulta indispensable, ante las deficiencias producidas por esta visión de túnel, retomar los contenidos subyacentes a toda norma, es decir, el sustrato deontológico y axiológico presente en toda regla positiva, pero sin llegar al exceso de desconocer y descartar la forma fundamental, ya que "(...) no hay materia sin forma ni forma sin materia (...)" (7). Para lograr el cometido de certidumbre jurídica y justicia del Derecho, hay que tratar el asunto de estructuras y contenidos desde una óptica conciliatoria y no antitética, toda vez que los conceptos abonan el terreno para una posterior fundamentación de contenidos.

Es gracias a Gustav Radbruch que la filosofía del Derecho retoma su cauce, cual es la búsqueda de la diferencia del Derecho justo e injusto. Y como la reducción de la iusfilosofía a una comprensión cerrada de las formas (positivismo jurídico) o de los contenidos (Derecho natural extremo) va en contravía de la realidad del Derecho en su totalidad, nace como imperativo encontrar una alternativa distinta, una "tercera vía" (7), sobre la cual la filosofía del Derecho enfilará todas sus baterías con el objeto de delinear de manera más precisa el límite entre lo justo y el entuerto.

\section{El concepto de filosofía del Derecho y la superación de la falacia naturalista}

El concepto de filosofía del Derecho es mucho más amplio que el de amor a la sabiduría del Derecho. Resulta necesario aunar el discurrir filosófico, caracterizado por ser especulativo, general y transistemático, con el jurídico, logrando así una disertación sobre los fundamentos de la ciencia particular del Derecho, mas no de una forma totalizadora, ya que se deja abierta la puerta para la renovación y el perfeccionamiento de sus contenidos.

Así las cosas, es posible definir la filosofía jurídica como “(...) una rama de la filosofía, no circunscrita a una de las parcelas de las ciencias jurídicas [así se destierra totalmente cualquier eventual confusión con la teoría general del Derecho], que persigue una aproximación intelectual al fenómeno jurídico desde un horizonte omnicomprensivo" (8), y que además cuestiona el conocimiento producido por el jurista y al Derecho positivo. De la definición ofrecida por el profesor Agudelo, salta a la vista que la filosofía del Derecho aborda los problemas fundamentales del Derecho mediante un ejercicio crítico e integrativo de otras disciplinas afines al conocimiento jurídico, además de las categorías ofrecidas por la dogmática jurídica.

Empero, dicha conceptualización puede ser vista por algunos sectores como metafísica, toda vez que su telos es el Derecho justo, lo que debe ser. Esta aparente dificultad de derivar 
juicios deontológicos partiendo de premisas ontológicas es lo que se ha denominado como falacia naturalista. Esta es conciliada a través de los derechos humanos, que son un referente de lo que el Derecho debe aspirar a ser, sin recurrir a argumentaciones emotivas o irracionales. Baste agregar que este análisis ha de partir desde una visión tridimensional del Derecho, es decir, donde esté la realidad jurídica considerada como norma, hecho social y valor.

\section{Caracteres del análisis iusfilosófico}

Sin perjuicio de que el maestro de Munich, Arthur Kaufmann, haya aseverado que el objeto formal de la filosofía del Derecho es indefinido por tratarse de la realidad jurídica en toda su extensión, ello no obsta para que el estudio filosófico-jurídico sea de carácter concreto, ya que a través de este es dable conciliar validez y eficacia normativas con las otras dos dimensiones: justicia (dimensión valorativa) y legitimidad (dimensión fáctica). De esta manera, el discurso normativo puede desbordar el ámbito de la supuesta legalidad sacrosanta, pues su fundamento último en determinadas concepciones materiales otorgará la aceptación tan necesaria e inseparable a un poder que pretenda erigirse como jurídico.

Así mismo, es una actividad de corte racional, polemizadora y cuestionadora, pues también propende por "(...) el concepto de Derecho, (...) las posibilidades de conocimiento de su objeto y (...) define unos criterios mínimos a los que en el orden axiológico ha de aspirar el Derecho (...)" (8). La búsqueda del concepto de Derecho no persigue establecer una noción única, definitiva y absoluta; todo lo contrario: pretende brindar elementos de juicio pertinentes que sí faciliten dilucidar los múltiples matices que giran en torno al Derecho de manera genérica, para así ser aplicables a cualquier sistema jurídico. Las mismas premisas son aplicables en cuanto al conocimiento de su objeto. Pero lo que ha de requerir el mayor esfuerzo por parte de los iusfilósofos es el delineamiento del contenido axiológico, descartado en otras épocas. Es bajo estos supuestos que será posible morigerar la arbitrariedad y el abuso del Derecho.

Como ya se indicó, el cuestionamiento dentro de la filosofía jurídica es transistemático, es decir, sale de su propia esfera para penetrar en otros ámbitos donde el Derecho o la filosofía también intervienen. En cambio, la dogmática jurídica es intrasistémica, pues su actividad reflexiva no va más allá de su bagaje conceptual. En este orden de ideas, la filosofía del Derecho comparte las mismas fuentes de la filosofía en general, yendo así más lejos que la dogmática jurídica y la teoría general del Derecho, previniéndose con ello de caer en un cientificismo o filosofismo (7). Además, no tiene un método formal establecido que deba usarse como único derrotero.

\section{Justificación de la filosofía del Derecho}

Es defendible la iusfilosofía en la medida que es una gran herramienta emancipadora del paradigma formal y legalista dejado por un Derecho positivo meramente descriptivo, pues se 
reitera nuevamente la necesidad de estructuras lógico-formales impregnadas de contenidos justos y legitimadores.

En consonancia con lo anterior, el punto básico que justifica la filosofía del Derecho es la racionalidad práctica que ve la luz dentro de un marco reflexivo, y que es la sumatoria de lo mejor de las racionalidades formal y material, dándose así un espacio ético y político cuyo norte es la teoría de la justicia. Es, pues, una mirada siempre dubitativa ante lo ofrecido por el Derecho positivo o legislado. Y como corolario se desprende que siempre en sus temáticas (ontología jurídica, epistemología jurídica y teoría de la justicia o estimativa jurídica) estará presente una permanente actitud cuestionadora hacia el ordenamiento jurídico.

\section{Objeto y temáticas de la filosofía del Derecho}

En cuanto a su objeto, existen dos posturas. Una de ellas es la ofrecida por Kaufmann, quien aduce que la filosofía jurídica carece de un objeto material, dado el carácter general y omnicomprensivo de la misma, y que en razón de ello el objeto formal (especial perspectiva desde la que se investiga un fenómeno en toda su extensión) es la totalidad del Derecho. Desde este punto de vista, el objeto de la filosofía del Derecho es imposible de delimitar, porque abarca toda la realidad jurídica. (7)

La segunda posición es la defendida por el jurista escandinavo Alf Ross, para quien sí es posible identificar el objeto de la iusfilosofía, pero vinculado más a la filosofía como método que como teoría. Aquí hay un punto de divergencia con la concepción kaufmanniana, toda vez que esta concepción no distingue si la filosofía se usa como método o como teoría. Volviendo con Ross, desde su punto de vista, la filosofía del Derecho no tendría un objeto total o indeterminado sino más bien claramente trazable, a saber, la ciencia del Derecho y sus distintas ramificaciones. Así, la filosofía del Derecho está por encima de la ciencia jurídica, pues aquella cuestiona categorías que en esta son aceptadas sin más reparos.

El profesor Agudelo asume en su trabajo la postura de Alf Ross, pues para abarcar el Derecho Procesal en su totalidad es necesario esclarecer su objeto, a fin de dar paso así a la labor crítica de la filosofía del Derecho Procesal. Por esta razón, surge la necesidad de apartarse de la argumentación ofrecida por el profesor Kaufmann, dada su vaguedad y alto grado de abstracción, no implicando necesariamente una confusión de ciencia y filosofía del Derecho, desconociéndose así "... las problemáticas inherentes al ser del Derecho y a la justicia, espacios en los cuales el filósofo del Derecho asume una tarea compleja de investigación y profundización". (7)

En lo atinente a las temáticas de la filosofía del Derecho, estas habrán de responder dos preguntas capitales, formuladas por el profesor Kaufmann: ¿qué es Derecho justo? y ¿cómo se realiza o conoce ese Derecho justo? Se desprende, prima facie, que la temática de mayor 
relevancia para este autor, y por razones evidentes, es la teoría de la justicia, de tenor racional y que sirva de contrapeso al Derecho positivo. De contera, deberá ser necesario el desarrollo de una teoría relativa a la validez del Derecho positivo que permita juzgar si este es conforme a unas reglas de estricta observancia que le garanticen eficacia y legitimidad.

\section{Filosofía del debido proceso}

Reflexionar sobre la realidad del Derecho Procesal en torno de sus problemas o discusiones es muy importante, por ser este instrumento idóneo para la materialización de un orden justo de convivencia y no objeto de espinosas controversias en cuanto a sus categorías fundantes. Así, resulta muy afortunado e intelectualmente provechoso abordar el concepto y contenido del Derecho Procesal, cómo es posible su conocimiento y qué teorías buscan encaminarlo hacia la producción de un Derecho correcto justo.

En consecuencia, el objetivo será sentar una postura crítica que trascienda la mera exposición sintética del contenido, en el entendido de que solo es posible a través de un ejercicio analítico, contextual y cuestionador.

\section{De la necesidad de una filosofía del Derecho Procesal}

Merced a una fundamentación iusfilosófica, el Derecho Procesal podrá erguirse como autónomo y único. Una filosofía del Derecho Procesal ha de reparar el error común consistente en la supremacía del Derecho sustantivo, pues la relación entre ambas ramas no debe ser antagónica o excluyente, ni vertical, sino de mutua cooperación y horizontalidad.

Su principal objetivo es brindar una fundamentación racional crítica de los contenidos normativos y otorgar legitimidad al ordenamiento jurídico procesal. Para ello, ha de contar con sólidas bases axiológicas y nomoárquicas. Desde la perspectiva rossiana, los temas de la filosofía del Derecho Procesal serán: la teoría del Derecho, que delimita las bases del Derecho Procesal al ser estudiado tal cual es y busca la naturaleza del Derecho Procesal y su ordenamiento jurídico; la teoría del conocimiento jurídico, que indaga por los elementos esenciales para abarcar la complejidad del objeto del Derecho Procesal, sentando su metodología y finalidad; y la teoría de la justicia, en la cual se estudian los institutos procesales a partir de su carga axiológica, teniendo como presupuesto la existencia de un Derecho justo.

Es solo bajo estos supuestos que se logrará una correcta administración de justicia, una idónea materialización de las políticas estatales, y por último-lo que resulta más trascendental-, la concreción de la cláusula social de nuestro Estado de derecho. 


\section{REFERENCIAS BIBLIOGRÁFICAS}

1. Ticona, V., El debido proceso y la demanda civil, Lima, Perú, Ed. Rodhas, 1999.

2. Olivera, J., "Fundamentos del debido proceso". Artículo publicado en la Conferencia Episcopal de Acción Social.

3. Chichizola, M., "El debido proceso como garantía constitucional”, en: Revista Jurídica La Ley, Buenos Aires, Argentina, 1983.

4. Torres, J., "Breves consideraciones acerca del debido proceso civil”, 2010, 12 pp. Disponible en: http://www.derechoycambiosocial.com/revista $021 /$ debido $\% 20$ proceso\%20civil.pdf (consultado el 12 de enero de 2012).

5. Kaufmann, A., Filosofía del Derecho en la posmodernidad, Bogotá, Colombia, Temis S. A., 2007.

6. Ospina, W., Es tarde para el hombre. Bogotá, Colombia, Norma S. A., 2006.

7. Kaufmann, Arthur, Filosofía del Derecho. Bogotá, Colombia, Universidad Externado de Colombia, 2006.

8. Agudelo, M., Filosofía del Derecho Procesal. Bogotá, Colombia, Leyer, 2006.

9. Vargas, A., ¿Es realmente neutra la norma procesal?, Medellín, Colombia, Temas Procesales, 1989.

10. Larenz, Karl, Metodología de la ciencia del Derecho.

11. Real Academia Española, Diccionario de la lengua española, España, Editorial Mateu Cromo-Artes Gráficas S. A., 2001.

12. Cabanellas, G., Diccionario jurídico elemental. 


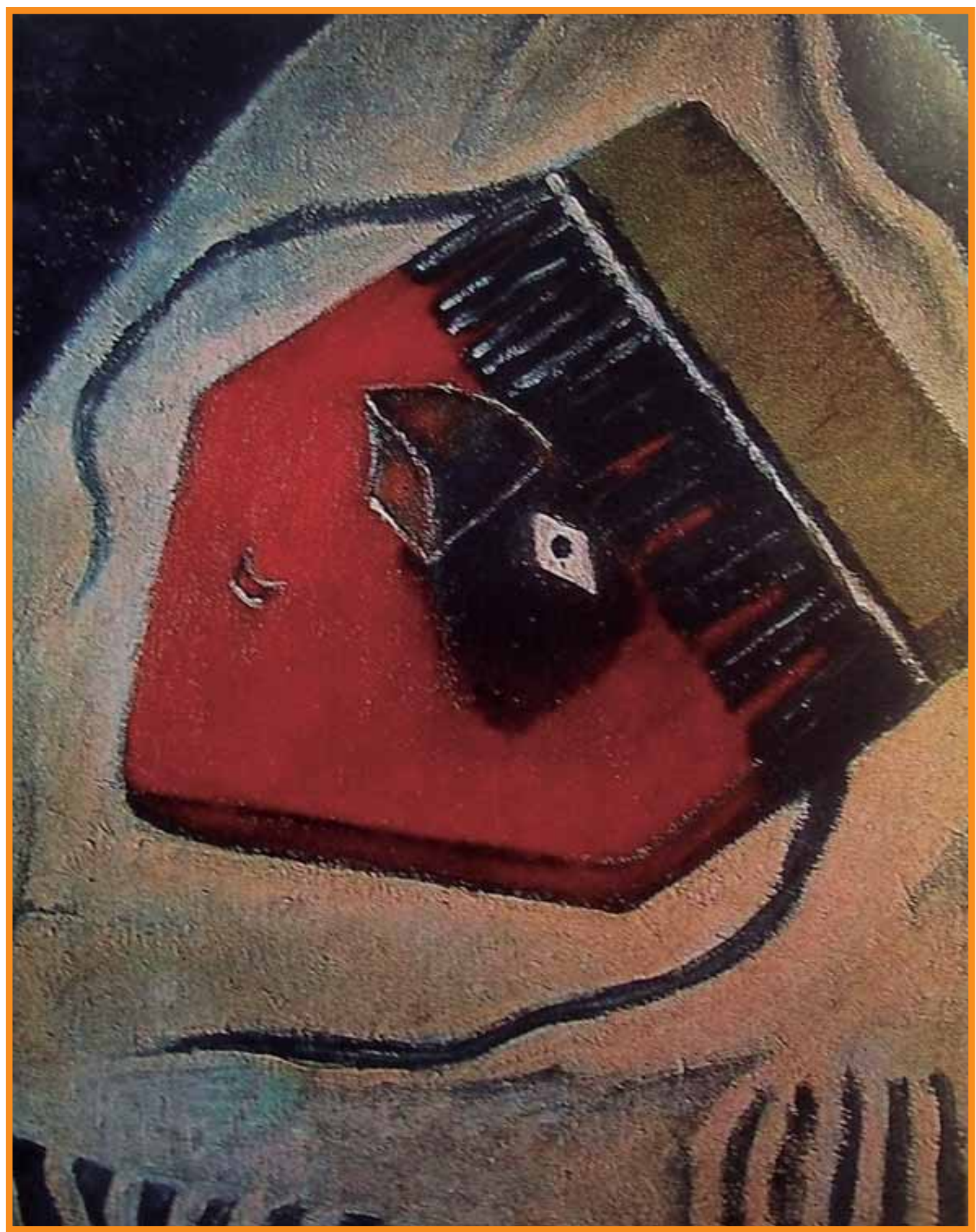

Máscara india. 